\title{
Connecting Patients, Practitioners and Regulators in Supporting Positive Experiences and Processes of Shared Decision-Making: A Case Study in Co-production
}

\author{
Fiona Browne, Steven Bettles, Stacey Clift, and Tim Walker
}

\subsection{Introduction}

The aim of the project in osteopathic regulation described in this chapter was to develop resources that could be used by osteopaths and patients to support them to make more explicit what was important to them and to enhance patient agency through shared decision-making. The project, which built in part on a background development programme in values-based osteopathy, ran in two main phases: Phase I focused on increasing understanding of the values of osteopaths, their patients and the regulator; Phase II focused on developing support resources. As will be seen, an understanding of the cultural values of osteopathy proved to be central to both phases of the project though in very different ways. In the first phase, cultural values proved to be relatively simple to elicit and to organise into a shared framework of values (see below), but in the second phase, the framework turned out to be very difficult to apply in practice.

The project was guided by two themes of growing importance across contemporary health service regulation: the need to support good practice as well as preventing bad practice [1, 2]; and the use of more evidence-based approaches [3, 4]. In relation to these themes osteopathy offers a promising area for exemplar projects in that studies have reported very high levels of care, for example with up to $95 \%$ overall patient satisfaction in the OPeN study [5] and similarly in a YouGov study [6] using categories derived from the CARE Measure [7]. Within this overall figure, however, items that related to patient empowerment in the context of shared decision making stood out as an area for potential improvement from the perspective of patients. The items included: 'fully understanding your concerns'; 'helping you to take control'; and 'making a plan of action with you' and were suggestive of a potentially paternalistic approach to care by practitioners. Hence the focus of our project on patient empowerment and shared decision-making.

F. Browne $(\bowtie) \cdot$ S. Bettles $\cdot$ S. Clift $\cdot$ T. Walker

General Osteopathic Council, London, UK

(C) The Author(s) 2021

D. Stoyanov et al. (eds.), International Perspectives in Values-Based Mental

Health Practice, https://doi.org/10.1007/978-3-030-47852-0_45 
The project as a whole is described in detail elsewhere [8]. We focus in this chapter on the insights it provided about the role of cultural values as a bridge between osteopaths, their patients and the regulator. We start with a case narrative illustrating the impact of the cultural values of osteopathy in practice.

\subsection{Case Narrative: Jennifer's Story}

Jennifer's story is fictitious but based on a composite of cases from everyday osteopathic practice. The story is presented here as it was used in the background development programme in values-based osteopathy on which the project was in part based. It is presented here as it was used in the context of that development programme, that is, in two parts with two brief questions for the reader at the end of the first part, about his or her reactions to that point.

\subsubsection{Part 1: Initial Assessment and Treatment}

Jennifer is a middle career manager working full-time in a medium sized media business. Her background is in design, but these days she spends most of her time in mainly administrative roles, sitting at a computer plus travelling to consult with business clients. She enjoys her job, but the current economic climate has made it difficult to find new clients and she says there are rumours of redundancies going round the business. She has been in her job for some years so she thinks she is safe, but these days who knows?

She visits an osteopath complaining of headaches and aching across her shoulders and upper back with an occasional pain into her left arm when she's particularly stressed or tired. It has been slowly developing over the last few months. She hasn't seen her doctor for fear of what she might say and because she doesn't want to start on a regime of pill taking.

Otherwise she is in good health with no history of significant illnesses or operations, though she did have a fall from her horse when she was 15 and was badly concussed. They told her she'd had a minor neck injury. She recovered ok and isn't aware of any repercussions from the accident. Her weight is within normal ranges and she claims to eat well, though she has little time for regular exercise, something she used to do a lot of when younger.

She is married with two teenage boys who are both into competitive sport. This involves them in frequent competitions as well as training sessions during the week.

When the osteopath examines her standing and moving, Jennifer looks tense and a little 'ill at ease', but she says she feels comfortable. Her upper thoracic and cervical spinal movements are all a bit less than the osteopath expects for someone her age, and there is considerable hypertonia (tension) in the paraspinal muscles. There is no dizziness on neck movements.

When the osteopath examines her lying supine, Jennifer flinches when he feels round her neck. The osteopath asks her if she has pain, which she denies but then 
goes quiet. The osteopath senses there is something wrong, but he doesn't know what it is and there is no further discussion about this. The osteopath finds a local area of restricted mobility in C 2-4 and Jennifer tells him that it feels tender particularly on the left side.

The osteopath concludes that her problem is mainly stress related, and that pressures of work and home are maintaining hypertonic tissue, impairing fluid flow in the area and that there are mild inflammatory changes in the soft tissues. He treats using some gentle soft-tissue techniques and joint articulation with the aim of freeing the area and improving fluid exchange.

\subsubsection{Questions for the Reader}

From either a patient or an osteopath perspective please think about.

1. What was good about the osteopath's approach to helping Jennifer?

2. Were there areas where they showed less than optimal practice?

We will come back to these questions later but for the moment please think about them particularly with issues of patient empowerment and shared decision-making in mind, and how these issues might interact with cultural and other values.

\subsubsection{Part 2: First Follow-Up}

Jennifer returns for a follow up appointment a few days later. She reports that she felt very sore for 36 hours after treatment but that has now eased and if anything, she feels a little better overall. While she is being examined and given further treatment for her neck, there is an awkward silence and then she says that perhaps she ought to explain that she was sexually abused by a relative when she was a child, which also included threatening her never to say anything to anyone. He had reinforced that message by putting his hands around her throat. Since then she has never felt comfortable lying exposed and she can freak out if someone puts their hands around her neck.

\subsection{Understanding Jennifer's Story}

Rather than commenting directly on Jennifer's story from our perspective as a regulator, we will explore the issues it raises through materials from our workshops. Being co-produced, these materials reflect the perspectives of us as a regulator, osteopaths and osteopathic patients. We give a brief overview of the project as a whole and then illustrate its outcomes with sample findings from two of the workshops, one from Phase I (eliciting values) and one from Phase II (developing support materials). 


\subsubsection{The Co-development Workshop Programme}

Three development workshops were held between 2014 and 2017. The first two workshops (Phase 1) focused on eliciting values and employed methods adapted by a senior academic in the University College of Osteopathy (formerly the British School of Osteopathy), Stephen Tyreman (see Acknowledgements), from those developed for surgical training by the Collaborating Centre for Values-based Practice in Oxford.

The last workshop (Phase II) focused on developing support resources was run in partnership with another regulator (the General Dental Council). For this workshop, we employed an independent social research organisation, Community Research, working with the team responsible for Phase I. We present here sample materials from the two phases of the project by way of illumination of the issues raised by Jennifer's narrative above.

\subsubsection{Phase I Workshop Materials: What Makes a Good Osteopath}

The focus in this first phase was on the values by which good practice in osteopathy is defined from the perspectives, respectively, of regulators, osteopaths and their patients. Stephen Tyreman (for the University College of Osteopathy) and Bill Fulford (for the Collaborating Centre) developed and led this phase using interactive exercises adapted, as noted above, from the values-based training materials developed in Oxford) and case studies.

Table 45.1 illustrates the key outcome from one of the interactive exercises in Phase I. Participants were asked to write down three words that they felt described a 'good osteopath'. It was emphasised that they should approach this not as a theoretical or general exercise but from their own particular perspective, whether as an osteopathic patient, an osteopath or other (the latter included regulators). The result was a wide diversity of responses with no obvious or outstanding differences between the three groups. We noted that all three groups agreed that a good osteopath showed a combination of

- People-focused values: care/empathy/compassionate/reflective.

- Task-focused values: skills/techniques/expertise/knowledge/experience.

This finding was encouraging from a regulatory perspective in that these shared values corresponded with the Osteopathic Practice Standards (core standards of conduct and competence for osteopaths) and other established regulatory standards for health professionals (see Guide to Further Sources, below). They thus provided prima facie validation of the role of these standards in supporting shared decisionmaking. Applying these findings to the story of Jennifer and others like it, we can see that the shared values illuminated both positive and negative aspects of osteopathic practice. Thus, on the positive side, we could say that the osteopath performed well against task-focused values: they made a technically competent 
Table 45.1 Descriptions of a 'good osteopath' from patients, osteopaths and regulators

\begin{tabular}{|c|c|c|}
\hline Patients & Osteopaths & Other (including regulators) \\
\hline Patient centred (1) & Effective (1) & Expertise (1) \\
\hline Efficacy (1) & $\begin{array}{l}\text { Professionalism } \\
\text { (1) }\end{array}$ & Knowledgeable (1) \\
\hline Accuracy of outcome (1) & Reflective (1) & Clinically sound/competent (1) \\
\hline $\begin{array}{l}\text { Identifying and improving condition } \\
\text { (1) }\end{array}$ & & Integrity (1) \\
\hline Professionalism (1) & & Trustworthy (1) \\
\hline Confidence in their ability (1) & & Good listener (1) \\
\hline \multirow[t]{3}{*}{$\begin{array}{l}\text { Communication interaction in } \\
\text { identifying needs (1) }\end{array}$} & & $\begin{array}{l}\text { Clear communication of } \\
\text { management plan (1) }\end{array}$ \\
\hline & Compassionate (3) & \\
\hline & Empathy (3) & \\
\hline Caring (3) & Care (3) & Caring (3) \\
\hline \multirow[t]{2}{*}{ Empathic/empathy (3) } & Empathy (3) & \\
\hline & Integrity (3) & Integrity (3) \\
\hline Competent (3) & & Competent (3) \\
\hline
\end{tabular}

[Note: Bold italic $=$ Task-focused values; Italic $=$ People-focused values; Bold $=$ other values $]$

osteopathic assessment of the presenting problem and provided appropriate treatment and follow-up for the patient that she found helpful.

On the other hand though, we could say that the osteopath performed less well against people-focused values: the osteopath misread Jennifer's hesitations and silences about being examined. Indeed, the osteopath's whole approach, at least as represented by the language of the case study, reflected a lack of engagement with what was important from the patient's perspective-the language is focused on what the osteopath thought, for example, 'the osteopath concludes that ...'-and there is no suggestion (in the story as presented) of the osteopath taking time or giving Jennifer space to say what was important to her about what was going on.

This mismatch of values goes to the heart of the challenge we had set ourselves as regulators of embedding standards. It could be assumed that despite the osteopath not really exploring what was actually important to the patient at that time, she might well have rated him within that $95 \%$ positive satisfaction for the profession as a whole (noted above, [5]). After all, measured against the task-focused values, the osteopath had done well-Jennifer did feel better. But the osteopath did less well measured by the people-focused skills - they missed (or misread or failed to respond to) important signals relevant to empowering Jennifer: in the terms of the CARE Measure items ([7] and see introduction above), the osteopath did not appear to be 'fully understanding (Jennifer's) concerns', or to 'help (her) to take control', and to 'make a plan of action with (her)'. 


\subsubsection{The Cultural Values of Osteopaths and Jennifer's Story}

The origins of these misreadings in the cultural values of osteopaths became clear through the workshop discussions in Phase I. As described further in the sources given below (see Guide to Further Sources), osteopathy is a manual therapy with palpation of tissue quality and mobility being key to patient care. The findings from palpation furthermore can only be interpreted in the light of a full background history. When this is done well, the patient will often feel they have been really listened to-a key component, as many among our participants pointed out, of the high patient satisfaction ratings achieved by osteopaths.

Osteopaths, moreover, tend to undertake a global assessment of a patient's musculoskeletal system rather than just the symptomatic area [9]. Hence, osteopaths will often request that patients undress so as to facilitate a broad osteopathic examination. Osteopathy thus tends to be by its nature an intimate intervention-it involves close physical contact with the patient in varying degrees of undress and so potentially feeling nervous and uncomfortable can be a common patient response. Couple this with the fact that osteopaths often work as sole practitioners in quite isolated practices, and the potential for misunderstanding becomes clear.

\subsubsection{A Draft Framework of Values}

Based on the above findings about the cultural values guiding osteopathic practice and their prima facie relevance to regulatory standards, and working with our academic partner, Professor Stephen Tyreman, our programme developed the framework of values shown in Fig. 45.1.

Our idea at this stage was that the framework would help to illuminate what was important to patients and practitioners by supporting them to make more explicit the values driving their interaction. Through improved understanding the framework would thus serve as a basis for developing support materials for improving patient agency and shared decision-making. When we came to test this idea, however, with an extended group of participants and additional cases, we found that far from clarifying the values involved, the Framework became a distraction. Participants struggled to map their values onto the Framework and ended up instead debating the merits of the Framework itself. It was at this point that we had the opportunity to partner with the General Dental Council in taking the project to its next phase.

\subsubsection{Phase II Workshop Materials: Developing Support Resources}

The General Dental Council had worked successfully with the independent research group, Community Research, who suggested an innovative approach to tackling the challenges of implementing shared decision-making directly. Using an exercise developed by Community Research with the steering group for the project, called 


\section{Framework}
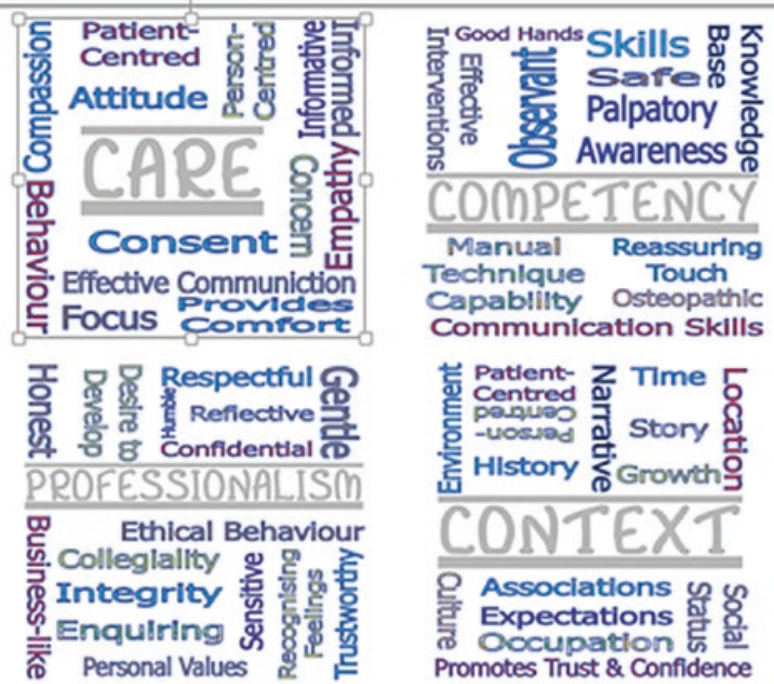

Communication Skills

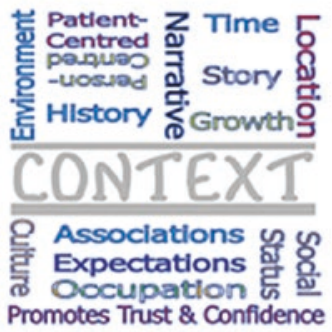

http:I/valuesbasedpractice.org/

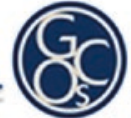

General Osteopathic Council

Fig. 45.1 Draft framework of shared values for osteopathic practice (The copyright of this figure is the property of the General Osteopathic Council. It was developed in partnership with Professor Steven Tyreman (see text and Acknowledgements) as part of the Council's programme described in this chapter)

'Fruits, Pests and Roots', this involved participants identifying, respectively, the benefits of and barriers to patient empowerment and a positive consultation, and actions that could be introduced to overcome the barriers. Written on coloured postit notes, these were then added to a tree diagram as shown in Fig. 45.2.

This exercise was helpful particularly in pointing to the diversity of factors participants identified across the board in relation to shared decision-making. This finding went some way to explaining the gap in our Phase I findings between the relative ease with which we were able to identify key cultural values and the difficulties we experienced when we came to applying them in practice. This in turn suggested that there could be 'no one size fits all' approach to developing support resources for patient empowerment and shared decision-making.

\subsubsection{Developing Prototype Support Resources}

Taking into account the 'no one-size-fits-all' finding from the workshop programme, the team has developed a series of different tools to support patients and practitioners to prepare for consultations that would enhance patient empowerment and 
Fig. 45.2 Fruits, pests and roots exercise from Phase II

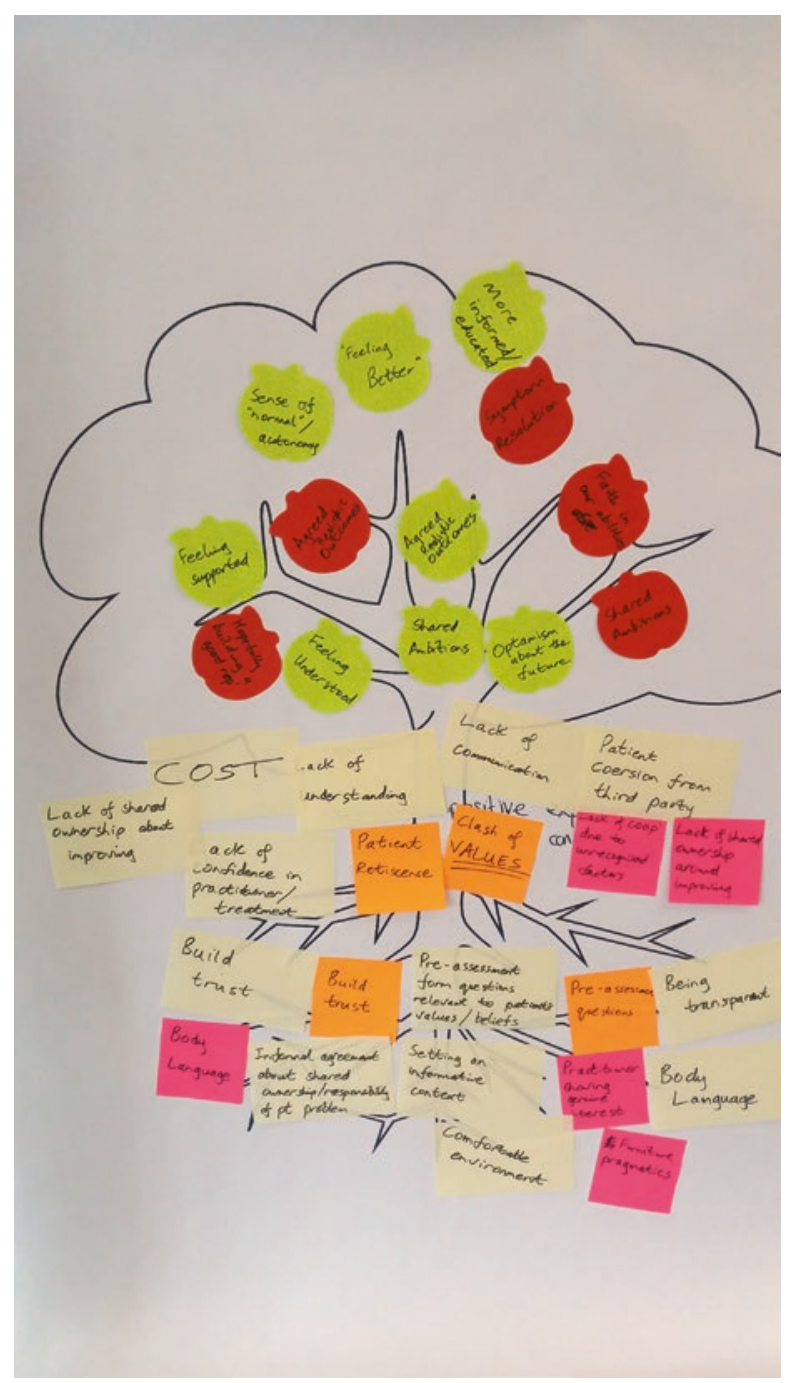

shared decision-making. Reflecting regulatory guidance and recent changes in the law on consent [10], this has included raising awareness of the values (of what is important to) the particular patient concerned [11]. As in Jennifer's story, this is not always self-evident: Jennifer presented with pain and stiffness in her neck, but her response to being examined pointed to underlying concerns that limited her engagement and there was little, if any, evidence of shared decision-making. These resources are listed with links below (see [8] and Guide to Further Sources). As noted earlier, they have been generally well received, at this early stage, and we plan more formal testing of their impact in the next stage of the project. 


\subsection{Conclusions}

In this chapter, we have described a two-phase project that we developed in our role as regulator, aimed at enhancing patient empowerment and shared decision-making in the context of osteopathic clinical care by supporting patients and osteopaths to make more explicit what is important to them in a consultation. The first phase of the project, concerned with eliciting values, showed the potential role of shared values as a bridge between patients, practitioners and regulators. When it came to implementation, however, in the second phase of the project, building on these values proved considerably harder than we had anticipated. What became clear was that a 'no one-size-fits-all' approach would be needed to support implementation. Examples of the range of support resources we are currently developing are provided below in our Guide to Further Sources.

Osteopathy as we have indicated is a promising area for work of this kind given the high levels of patient satisfaction generally achieved by osteopaths. Lower scores, however, for items indicating patient empowerment and shared decisionmaking are important, as we have also indicated, particularly from a regulatory perspective to the extent that these are reflected in recent changes in the law on consent $[10,11]$. Jennifer's story in this chapter shows the importance of cultural values underpinning both positive and negative aspects of osteopathic practice. Insights into these values emerged readily in Phase I of our project. That such insights are, however, not sufficient was made abundantly clear by the difficulties of implementation we encountered in Phase II. These difficulties we believe suggest the need for building further on contemporary moves in health service regulation towards empirically informed approaches to supporting good practice.

Acknowledgements We would like to warmly acknowledge the support and guidance of:

- Harry Cayton, at the time of the project, Chief Executive of the PSA (Professional Standards Authority).

- Professor Stephen Tyreman of the University College of Osteopathy.

- Professor Bill Fulford of the Collaborating Centre for Values Based Practice.

- Mr. Guy Rubin of the General Dental Council.

- Ms. Rebecca Addis and Ms. Kate Waller of Community Research.

- All our patients and practitioners.We are grateful to the General Osteopathic Council and the General Dental Council for funding this project. The General Osteopathic Council employed all the authors at the time of the study but without requiring a grant number.

Sadly, Stephen Tyreman died before the end of the project. This was shortly after being awarded the Institute of Osteopathy President's Medal for 2018. For an appreciation of his work, please see: https://valuesbasedpractice.org/who-are-we-2/list-of-project-partners/list-of-individuals/ stephen-tyreman/. 


\subsection{Guide to Further Sources}

\subsubsection{The Osteopathic Practice Standards (2019)}

These are given here: https://standards.osteopathy.org.uk/.

They are consistent with the corresponding standards for medicine in the UK given in the General Medical Council's publication Good Medical Practice at: https://www.gmc-uk.org/ethical-guidance/ethical-guidance-for-doctors/ good-medical-practice.

\subsubsection{The Cultural Values of Osteopathy}

These are reflected, for example, in the curriculum elements included in the Guidance for Osteopathic Pre-Registration Education (GOPRE) at https://www. osteopathy.org.uk/training-and-registering/becoming-an-osteopath/ guidance-osteopathic-pre-registration-education/).

\subsubsection{Prototype Resources}

As noted in the chapter, we have developed a range of prototype resources to support patient empowerment and shared decision-making in osteopathy by helping patients and practitioners to make more explicit what is important to them in a consultation. These have been well received by practitioners and patients, and in a further phase of the project, we plan to assess their actual impact in practice. For details including links to the on-line resources please see [8].

\section{References}

1. Law Commissions. Regulation of Health Care Professionals Regulation of Social Care Professionals in England. Law Commission, Scottish Law Commission and Northern Ireland Law Commission. Report number: LAW COM No 345, SCOT LAW COM No 237, NILC 18, 2014. https://s3-eu-west-2.amazonaws.com/lawcom-prod-storage-11jsxou24uy7q/ uploads/2015/03/lc345_regulation_of_healthcare_professionals.pdf. Accessed 21 Dec 2019. Subsequent dialogue in relation to this is an example about this framing of regulation.

2. Tyreman S. Evidence, alternative facts and narrative: a personal reflection on person-centred care and the role of stories in healthcare. Int J Osteopat Med. 2018;28:1-3. https://doi. org/10.1016/j.ijosm.2018.04.005.

3. Professional Standards Authority. Rethinking regulation. 2015. https://www.professionalstandards.org.uk/docs/default-source/publications/thought-paper/rethinking-regulation-2015.pdf. Accessed 21 Dec 2019.

4. McGivern G, Fischer M, Palaima T, Spendlove Z, Thomson O, Waring J. Exploring and explaining the dynamics of osteopathic regulation, professionalism and compliance with standards in practice. Report for the General Osteopathic Council. 2015. http://www.osteopathy. 
org.uk/news-and-resources/document-library/research-and-surveys/dynamics-of-effectiveregulation-final-report/. Accessed 21 Dec 2019.

5. Leach CM, Mandy A, Hankins M, Bottomley LM, Cross V, Fawkes CA, Fiske A, Moore AP. Patients' expectations of private osteopathic care in the UK: a national survey of patients. BMC Complement Altern Med. 2013;13:122. https://bmccomplementalternmed.biomedcentral.com/articles/10.1186/1472-6882-13-122. Accessed 21 Dec 2019.

6. You Gov Public Perceptions Study. Report for the General Osteopathic Council. 2018. https:// www.osteopathy.org.uk/news-and-resources/document-library/research-and-surveys/publicperceptions-study/. Accessed 21 Dec 2019.

7. CARE Measure. The Consultation and Relational Empathy (CARE) Measure. http://www. caremeasure.org. Accessed 21 Dec 2019.

8. Browne F, Bettles S, Clift S, Walker T. Connecting patients, practitioners and regulators in supporting positive experiences and processes of shared decision-making: a progress report. $\mathrm{J}$ Eval Clin Pract. 2019;25(6):1030-40. https://doi.org/10.1111/jep.13279.

9. Tyreman ST. The concept of function in osteopathy and conventional medicine. $\mathrm{PhD}$ thesis, Milton Keynes: Open University; 2001. http://oro.open.ac.uk/59356/. Accessed 14 Jan 2020.

10. Supreme Court. Montgomery (Appellant) v Lanarkshire Health Board (Respondent) (Scotland). UKSC 11, 2015. https://www.supremecourt.uk/cases/uksc-2013-0136.html. Accessed 21 Dec 2019.

11. Herring J, Fulford KWM, Dunn D, Handa A. Elbow room for best practice? Montgomery, patients' values, and balanced decision-making in person-centred care. Med Law Rev. 2017;25(4):582-603. https://doi.org/10.1093/medlaw/fwx029.

Open Access This chapter is licensed under the terms of the Creative Commons Attribution 4.0 International License (http://creativecommons.org/licenses/by/4.0/), which permits use, sharing, adaptation, distribution and reproduction in any medium or format, as long as you give appropriate credit to the original author(s) and the source, provide a link to the Creative Commons license and indicate if changes were made.

The images or other third party material in this chapter are included in the chapter's Creative Commons license, unless indicated otherwise in a credit line to the material. If material is not included in the chapter's Creative Commons license and your intended use is not permitted by statutory regulation or exceeds the permitted use, you will need to obtain permission directly from the copyright holder.

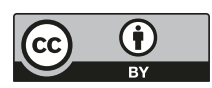

